\title{
Light and Temperature and the Reproduction of Plants*
}

\author{
By Prof. V. H. Blackman, F.R.S.
}

\section{EFFECT OF TEMPERATURE}

$\mathrm{T}^{\mathrm{H}}$ HE thermal effect, that of chilling, now to be considered, is one which is being closely investigated by numerous biologists. It is truly cryptic in nature, for the effect of the temperature change may long remain hidden, only showing itself at the time of flowering many weeks later. The process of chilling young plants in order to accelerate flowering appears to have been used by an investigator in the United States before 1857 to secure the early flowering of wheat; but it was first investigated by Gassner in 1918 in his study of the differences between spring and winter cereals. It is well known that a winter variety of wheat or rye if sown in the spring will usually not flower, that is, will not produce an ear at all during that season or will ear so late that no satisfactory crop can be harvested. Spring cereals, however, have not this disability. Gassner conceived the idea that delay in flowering of the spring-sown winter wheat might be due to the lack of exposure to chilling which the winter sowing ensures. Accordingly he exposed seedling plants of winter wheat for thirty days to a temperature a little above freezing point, with the result that they flowered about the same time as the spring varieties. The effect that may be produced is shown in Table II.

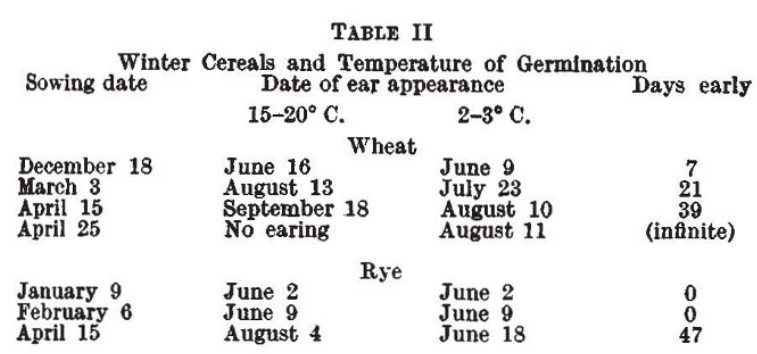

The method of chilling seedlings employed by Gassner is of course quite impracticable on an agricultural scale, since the delicate seedlings could only be sown with the most careful individual handling. It is evident that if the method is to be of any practical use some modification is essential. Such a successful modification has recently been achieved in Russia. There the growing season may be short, not only from delay in sowing owing to the lateness in the rise of the soil temperature, but also owing to excessive heat. In the semi-arid zones of the Ukrainian steppes,

* Continued from p. 934. for example, a period of great heat sets in during summer, and if the crop has not then ripened the plants are damaged, and the yield is very small. The modification in the chilling process which has been introduced by Russian botanists consists in exposure to the low temperature at a very early stage and under conditions which prevent almost entirely the growth of the embryo of the grain.

The grain is not fully soaked, but enough water is supplied to bring its moisture content up to fifty per cent of the dry weight of the seed. The amount of water must not be much less or the life processes in the embryo will not be sufficiently active to respond to chilling; the amount must not be much more or the embryo of the grain will develop too far. After the grain has been allowed to take up during twenty-four hours the appropriate amount of water at an ordinary indoor temperature, the grain is chilled by exposure to a temperature a little above freezing point $\left(34^{\circ}-36^{\circ} \mathrm{F}\right.$.) for a period of $10-15$ days. Since the temperature is low and the grain not fully swollen, the development of the embryo is so slight that the grain after treatment can be sown in the ordinary way. In fact, it can be dried and stored and sown many weeks later.

The process is known as vernalisution, that is, bringing to the spring state. The plants by this treatment are brought into the condition which a winter-sown wheat would have in the spring. The effect of the chilling is to hasten the occurrence of flowering. It reduces the length of the nonreproductive, the purely vegetative, part of the life-cycle of the plant. The similarity of this to the photo-periodic effect, with its control of flowering by length of day, is noticeable. We shall see later that the two effects are closely related

TABLE III

\begin{tabular}{|c|c|c|c|}
\hline Variety & $\begin{array}{l}\text { Date of ear } \\
\text { formation }\end{array}$ & $\begin{array}{c}\text { Days early }(-) \\
\text { or late }(+)\end{array}$ & $\underset{\text { yield }}{\text { Comparative }}$ \\
\hline \multirow{4}{*}{$\begin{array}{l}\text { Odessa Girka } \\
T \text {. erythrospermum } \\
\text { Vernalised } \\
\text { Untreated } \\
T \text {. ferrugineum } \\
\text { Vernalised } \\
\text { Untreated }\end{array}$} & July 14 & - & 100 \\
\hline & June 5 & -9 & $111 \cdot 7$ \\
\hline & & & \\
\hline & $\begin{array}{l}\text { June } 12 \\
\text { July } 1\end{array}$ & $\begin{array}{l}-2 \\
+17\end{array}$ & $\begin{array}{r}141 \cdot 1 \\
7 \cdot 9\end{array}$ \\
\hline
\end{tabular}

The effect of vernalisation on two wheats grown at Odessa which are exceptionally late in producing the ear, and so in the ordinary state are useless in the Ukraine, is shown in Table III, where they are compared with a Girka wheat which is 
especially suited to the local conditions. All were sown on April 11.

Unvernalised, these two wheats were 17 days later in earing than Girka, so that they gave an inconsiderable crop. By vernalisation, both varieties were ahead of the Girka variety in ripening and gave higher yields.

The facts of vernalisation are definite, but, as is the case with photo-periodism, the physiological processes in the plant which are responsible for the phenomena remain for the most part to be discovered. The two phenomena can scarcely be considered separately, for in the absence either of chilling or of the appropriate day-length, flowering may be long delayed or fail altogether. What is to be explained in each case is the manner in which the treatment chilling or alternation of light and darkness endows the plant with a potentiality for earlier flowering.

A theory has been put forward by Lysenko which attempts to provide a physiological basis for both the processes. It lays stress on the distinction between vegetative growth and the developmental stages associated with flowering. On this hypothesis the plant must pass through a number of stages before it reaches the stage necessary for flowering. Of these stages two are supposed to be sharply defined, first the heatstage (thermo-stage) and second, the light-stage (photo-stage), though these stages are not necessarily associated with actual growth. In this view, the external conditions are different for the two stages. For transition through the first stage winter cereals, for example, require a low temperature and a sufficiency of moisture and oxygen to allow of sufficient activity for response of the embryo to the low temperature; illumination is, however, not important. The later light-stage only begins after the completion of the heat-stage; it requires not a low but a moderate temperature, and in the case of the cereals an illumination of more than 10 hours a day, and as an optimum condition, continuous light. With a day shorter than 10 hours this stage cannot be completed and vegetative growth continues indefinitely. In this view, vernalisation by chilling results in the completion of the heat-stage without which the light. stage cannot begin and flowering cannot be achieved; long days then complete the work.

This theory may seem plausible at first sight, but living organisms are so complex that with them, unfortunately, a simple explanation is almost certain to be wrong. At the Imperial College, Gregory and Purvis for some years have been studying the behaviour of the winter cereals in relation both to the vernalisation and the photoperiodic effect. In the first place, it is unlikely on general grounds that such stages should be sharply differentiated-if they do occur one would expect them to merge into one another. In fact, however, the work of Purvis has shown that chilling is not essential for flowering. If winter cereals are grown throughout the winter in the greenhouse, flowering occurs without chilling in the lengthening days of spring; there is thus no sharply marked heat-stage.

The weakness of the earlier theoretical considerations of photo-periodism and vernalisation, as has been pointed out by Gregory, lies in concentrating attention on the later and less essential stages of development. In the earlier work on photoperiodism the opening of the flower bud was considered as the test of flowering. The bud, however, is initiated much earlier in the life of the plant, and when regarding the effect of previous external conditions upon flowering, attention would seem most properly to be focused on the stage of initiation of the flowers. This is usually very much earlier than the actual opening of the buds.

Klebs, many years ago, held that the stage of "ripeness to flower" had to be reached before the rudiments of the flowers were laid down, this being followed later by the stage of flower development and of expansion of the floral organs. The photo. periodic effect may be concerned mainly with the last stage. If attention is focused on flower initiation, the morphology of the plant cannot be neglected, as Gregory has insisted. The only plants which have been elosely investigated from this morphological point of view are the temperate cereals, rye, barley, wheat, by Purvis at the Imperial College. These, as is well known, have a terminal inflorescence, a certain number of leaves being produced on the main axis before the rudiments of the flowers appear. It has been shown that the number of leaves produced before flowers are formed is dependent upon external conditions. Purvis has demonstrated that the effect of chilling is to reduce the number of leaves formed; thus flower formation begins earlier and so flowering is accelerated. By vernalisation at $1^{\circ} \mathrm{C}$. for six weeks the number can be reduced to 13 in ryo and recently 9 has been achieved; by very pro. longed vernalisation for six months the number in wheat has also been reduced to 9 .

It has also been shown that vernalisation is a process which takes place by degrees; even a few days' chilling produces some effect. In an experiment by Gregory and Purvis in which vernalisation was applied to rye for $4,7,11,14,21,28,35,42$ and 49 days, there was some effect at 7 days and the effect was progressive up to 49 days. A further and most suggestive result has been obtained by Gregory and Purvis from these experiments. The number of days of vernalisation added to the number of days between placing the plant under 
growing conditions and the opening of the flowers (anthesis) tends to be constant. It would appear then that vernalisation produces no actual acceleration of flowering, since there is no reduction in the time elapsing between the moistening of the grain and the occurrence of flowering. The apparent acceleration is due to the reduction in the number of days in the growing post-vernalisation period.

There is a further interesting point. The number of leaves formed not only responds to chilling but also to length of day. The temperate cereals are described as long-day plants, for their ears emerge in long days. In the winter forms, however, flower-formation takes place much more rapidly in short days, while spring forms do not exhibit this need. The effect of chilling winter forms is to make them independent of short days, so that, like the spring forms, they will flower rapidly in long days.

We are still ignorant as to the action of vernalisation by cold. Is it a primary temperature effect on the plant processes, or does the low temperature merely act indirectly by keeping growth in check and so inducing a kind of semi-dormancy in which slow maturation processes go on without any morphological change?

\section{DARK VERNALISATION}

As has been already stated, the sub-tropical cereals, such as maize, sorghum and other millets, are attuned to the short days of the tropics, as are also cotton and the soybean, and have their flowering much delayed in long days. It has been discovered, however, that if the grain of sorghum or millet is kept in darkness for a period, the need for short-day illumination of the plant is removed. The grain must of course be soaked, but in contrast with the vernalisation of winter cereals a high temperature is required. The grain is given about 25 per cent of its weight of water and then kept in the dark for 5-10 days at a temperature of $27^{\circ}-29^{\circ} \mathrm{C}$. After this treatment the plants will flower in long days or even in continuous light; their cultivation can thus be extended to regions of long summer days. This is a considerable achievement and suggests that in such plants the absence of light is necessary for the occurrence of certain changes. What seems to be important is a certain 'dose of darkness'; when a sufficient measure has been given the plant is independent of further periods of night.

Some light has thus been thrown on the nature of photoperiodism and vernalisation by these studies of winter cereals, but the nature of the changes in the plant during the periods of darkness and chilling are still in the greatest obscurity. Two results of general interest, however, have come from these investigations of duckweed and winter cereals. One, the fact that physiological changes, which it is difficult to describe as other than development, can go on in a swollen, 'colddormant' seed incapable of growth. Secondly, there has been demonstrated the need for change if the plant is to run its full life-cycle. Duckweed may multiply best at a constant high temperature and continuous light, but for many plants when flowering is concerned, variation in the environment is essential. To them, one may say, uniformity is anathema. It is evident that this need for variety greatly complicates the physiological analysis of plant responses, for the effect of not one but many environments has to be investigated.

\section{Medical Research in 1935}

\begin{abstract}
$A S$ in previous years, perusal of the report of A the Medical Research Council* provides the reader with a broad view of the research work carried out in Great Britain in medicine and its allied subjects : from its pages, the trend of recent investigations can be quickly and easily followed. The increase in the grant-in-aid provided by Parliament enabled the Council to restore the cuts in salaries and to proceed with plans for new research work which had been temporarily in abeyance, and to undertake additional investigations required for the purposes of administrative

* Committee of the Privy Council for Medical Research. Report of the Medical Research Council for the year 1934-1935. (Cmd. 5079.) Pp. 183. (London: H.M. Stationery Office, 1936.) 38. net.
\end{abstract}

departments. Lord Dawson of Penn and Prof. A. E. Boycott retired from the Council, and Prof. J. A. Ryle and Prof. M. J. Stewart were appointed to succeed them. Towards the close of the period under review, the Council learnt of the impending retirement of its chairman, the Marquess of Linlithgow, on his appointment as Viceroy of India. The funds of the Council have been augmented as in previous years by sums of money for the promotion of particular schemes of research, provided by a number of different bodies. The Council is also responsible for the award of Rockefeller medical fellowships and Dorothy Temple Cross research fellowships in tuberculosis; the arrange- 